(5) constant attention to collections of water in gardens of houses and bungalows. In addition the segregation of Europeans was carried out to a limited degree, removing them from the vicinity of infected natives, treatment of all infected persons with quinine and the prophylactic use of quinine, the troops being paraded twice a week for this purpose. The results obtained were a distinct but not great diminution in the, number of Anopheles present in the houses, and a diminution in the admission rate for ague to 269 per Iooo, the lowest rate on record ( 1902 happened to be, however, an exceptionally healthy year). Captain James concludes that mosquito destruction, even though not obviously reducing the number of Anopheles, brings about a decrease in the amount of malaria, but is difficult to carry out and is expensive; apparently the campaign against the mosquitoes at Mian-Mir was not nearly so successful as that in Lagos. $\mathrm{He}$ attributes great value to the other measures, viz. the continued and systematic treatment with quinine of the native children, who are undoubtedly the chief source of infection, and the prophylactic use of quinine.

$$
\text { R. T. Hewlett. }
$$

\section{HENRY PERROTIN.}

THE cause of astronomical science in France has been deprived of another of its ablest advocates by the lamented death of $M$. Perrotin, the director of the observatory at Nice. For more than twenty years M. Perrotin has watched over the growth and directed the energies of that institution. It was his good fortune, through the munificence of M. Bischoffsheim, to be able to erect and arrange a well equipped observatory to his own design, unhampered by legacies from former benefactors or directors. How the work grew under his hand astronomers have long since recognised and appreciated. As each instrument was completed it was immediately devoted to some special purpose. The meridian instrument was employed to determine the difference of longitude between Paris and the observatory, and to complete the chain Paris-NiceMilan long before the observatory was in working order as a whole. The fifteen-inch equatorial was at work on double stars, planetary markings, comets, \&c., before the large instrument of thirty inches aperture, under the mammoth "floating dome," could be devoted to the more rigorous scrutiny of faint and difficult objects.

It is scarcely necessary here to direct attention to the industry that marked the career of the first director of the Nice Observatory, or to the value of the researches produced by the staff under his guidance and encouragement. The work of $\mathrm{M}$. Thollon on the solar spectrum may serve as a specimen in the department of spectroscopy. The discovery of many minor planets shows the care with which the photographic plates were taken and scrutinised. More particularly as the work of M. Perrotin, personally, should be mentioned his discussion of the inequalities in the orbit of Vesta, a research to which he devoted much time, interrupted as it must frequently have been by the care of the establishment under his charge. As an observer he was indefatigable, and devoted much time to the study of the faint markings on Venus, on Mars, and on Uranus. Aware that he was working at the extreme limit of visibility, and knowing the tendency for selfdeception to creep in and impair the value of such delicate observations, he sought opportunities of making similar measures and records with different instruments, and under varied conditions, in order to remove, so far as possible, the evils of bias and partiality from the results of his researches. Excessive No. I 794, vor. 69] and painstaking care marked his efforts to secure rigorous accuracy.

Apart from his astronomical work, properly so called, in the department of physics, he added another determination to those that have been made on the velocity of light, which we recall here mainly to show the varied character of his researches and the energy which he displayed in whatever he undertook. His life was a busy one, and he did not spare himself. The great monument that he has left behind is the magnificent observatory at Mont Gros, and his greatest service to science is perhaps the activity which he inspired in those by whom he was surrounded. At the comparatively early age of fifty-eight he has succumbed, but he leaves behind him a memory that will be long treasured by all those whose fortune it has been to assist him in earning the reputation that the young observatory at Nice has already won.

\section{NOTES.}

The Croonian lecture of the Royal Society will be delivered on March 24, the subject being "The Chemical Regulation of the Secretory Process," by Prof. E. H. Starling, F.R.S., and Dr. W. M. Bayliss, F.R.S. The Bakerian lecture will be delivered during May by Prof. E. Rutherford, F.R.S., of Montreal, on "The Succession of Changes in Radioactive Substances."

THE annual inspection of the National Physical Laboratory by the General Board will be held to-morrow, March 18.

Prof. Ostwald will deliver the Faraday lecture of the Chemical Society on April 19 in the theatre of the Royal Institution.

Prof. Agassiz has been elected a foreign associate of the Paris Academy of Sciences in succession to Sir George Stokes; and Prof. E. Warming, Copenhagen, has been elected a correspondant of the academy.

SiR ARthur RÜCKER will deliver the academic address at the close of the present session at the University College of North Wales, Bangor.

DR. ROBERT LUTHER has been appointed professor of physical chemistry at the University of Leipzig.

THE deaths are announced of Dr. Wilhelm Schnell, professor of mechanics and synthetic geometry at the Technical School of Carlsruhe, and of Dr. von Pallich, assistant in physics and director of the meteorological station at the University of Graz.

The Belgian Royal Academy has awarded its gold medal of 1000 francs to M. Marc de Selys-Longchamps for his memoir on the development of a Phoronis. The Theophile Gluge prize for physiology has been awarded to Dr. P. Nolf, of the University of Liège.

THE following have been elected associates of the Belgian Royal Academy (Classe des Sciences) :- Profs.. George Howard Darwin (England), Corrado Segre (Turin), Wilhelm Roux (Halle-sur-Saale), and M. Michel Lévy, of the French Geological Survey.

THE foundation of Schnyder von Wartensee offers, says Science, its prize of about $140 l$. for an essay on the climate of Switzerland during the last thirty-seven years. Essays, which may be in English, should be sent before September 30, 1906, to the library at Zurich.

A Reuter message from Rome reports that at $5 \cdot 30$ a.m. on March to a very violent earthquake shock, followed by four others, was felt at Magliano di Marsi. On the same 